\title{
Towards an Understanding of Low-Income Individuals' Financial Resiliency: Exploration of Risk Preferences, Personality Traits, and Savings Behavior
}

\author{
Carlos M. Parra*1, Ranjita Poudel ${ }^{2} \&$ Matthew T. Sutherland $^{3}$ \\ ${ }^{1}$ College of Business, Florida International University (FIU) \\ ${ }^{2 \& 3}$ Department of Psychology, Florida International University (FIU) \\ cmaparra@fiu.edu,masuther@fiu.edu,rpoudel@fiu.edu
}

\begin{abstract}
The Coronavirus disease 2019 (COVID-19) pandemic has helped expose and exacerbate individuals' and households' financial vulnerability worldwide. Meanwhile, behavioral elements affecting low-income populations' ability to save and become more financially resilient have yet to receive sufficient academic attention. This exploratory study aims at beginning to help elucidate the determinants of lowincome individuals' real-life savings behavior by utilizing laboratory performance measures (to characterize participants' risk preferences by using the Balloon Analog Risk Task - BART, in study 1), as well as self-report surveys (to characterize participants' personality traits, in study 2). Combining results from both studies, latent personality traits (i.e., attitude towards risk, perseverance, distractibility, and state anxiety) are found to affect the risk preferences of low-income individuals (captured using a novel BART performance measure indicative of an individual's strategic risk preference adaptation), which in turn impact their ability to successfully complete matched savings programs and, thus, their ability to save and enhance their financial resilience.
\end{abstract}

Keywords: Financial Vulnerability/Resilience, Low-income Participants, Matched Savings Programs, Personality Traits, Balloon Analog Risk Task (BART).

\section{Introduction}

According to the Center on Budget and Policy Priorities (CBPP) COVID-19 Hardship Watch, in the U.S. the "pandemic and the economic fallout have been widespread but are particularly prevalent among Black, Latino, Indigenous, and immigrant households" (CBPP, 2020, p. 1). Unfortunately, this calamitous situation should have been expected. Several studies prompted by the great recession of 2008 demonstrated how fragile and vulnerable Americans were to financial shocks. In particular, Lusardi (2011) examined Americans' self-reported ability to withstand shocks and found that "only 49 percent of respondents have set aside emergency or rainy day funds that would cover expenses for 3 months in case of sickness, job loss, economic downturn, or other emergencies. Thus, many families would not be able to draw on personal financial resources if hit by a shock" (p. 7). Ominously, in a similar study, "half of Americans report that they would probably or certainly be unable to cope" with "an unexpected need in the next month that required them to come up with $\$ 2,000 "$ (Lusardi et al., 2011, p. 9).

This may have triggered the Federal Reserve Board to ask respondents in 2013 how Americans would pay for a $\$ 400$ emergency, and implausibly, "47 percent of respondents said that either they would cover the expense by borrowing or selling something, or they would not be able to come up with the $\$ 400$ at all" (Gabler, 2016, p. 1). Since households' own savings are the resource used most often to deal with shocks (Lusardi et al., 2011), the COVID-19 pandemic is likely to have caught Americans in a period of widespread financial vulnerability, understood as the limited ability to withstand temporary economic setbacks (Gauthier \& Furstenberg, 2010). Unfortunately, low-income households and individuals worldwide were -and may continue to be- especially unprepared to face the more intransient adverse economic consequences of the COVID-19 pandemic. To make matters worse, academic research on low-income households' and individuals' savings behavior may be especially difficult to conduct. On the one hand, when low-income individuals manage to save, they would also be more likely to engage in asset building behavior and presumably to become less financially vulnerable (which would then make them less likely to conform to study parameters). On the other, when low-income individuals conform to study parameters, they would be more likely to follow the inclination not to save and/or build assets, presumably because they have repeatedly forgone the opportunity to do so in the past, and thus they would be study participants less likely to engage in the savings behavior under investigation. In particular, inaction inertia or the "inclination to resist an action after previously bypassing a similar action" (Westfall et al., 2012, p. 192) has been studied in the context of 
consumer promotional formats (Liu \& Chou, 2018), as well as of loss aversion in relation to sunk cost effects (Westfall et al., 2012). Crucially, inaction inertia has also been identified as individuals' reluctance to enroll in attractive savings opportunities induced by previous inaction (Krijnen et al., 2020). Conversely, and unsurprisingly, savings habits are associated with regular savings and thus matter for reducing the stress of financially difficult situations (Loibl et al., 2011). Because of this, it would not be counterintuitive to suppose that inaction inertia, perhaps compounded by misgivings and distrust of out-groups (especially those interested in financial matters), could be more pronounced in low-income settings (a research question that should be explored in a separate study). If this were the case, studies aimed at exploring low-income individuals' savings behavior would be more likely to fail, which may in part help explain their scarcity.

Despite this, and especially because of this, it is imperative to explore new and more effective ways to enhance low-income individuals' financial resiliency, so that they are better prepared to withstand future economic shocks associated with, for instance, another (but hopefully less devastating) pandemic, more frequent as well as more severe extreme weather events, or periodic economic downturns or recessions. Thus, in this study, we set out to explore the determinants of low-income individuals' real-life savings behavior by utilizing laboratory (lab) measures of individual risk preferences captured using the Balloon Analog Risk Task (BART) (study 1), and also by means of self-report surveys (to characterize personality traits) (study 2). To achieve this, we designed a six-month matched savings program (6mMSP) in alliance with a not-for-profit partner (Catalyst Miami). Before starting this 6mMSP, 24 low-income participants (recruited from a pool of Catalyst Miami clients) played a risky decision-making game called the BART. The intervention was conducted (before the pandemic's onset) in an effort to explore whether participants' performance while playing the BART (i.e., task performance metrics) could help predict their subsequent savings behaviors (i.e., real-life savings outcomes). Additionally, we used participants' BART and savings performance to explore associated latent personality traits. Finally, we explored whether BART performance measures mediated the relationship between latent personality traits and total savings. With this in mind, the following section describes various ways of enhancing financial resiliency and how financial behaviors (e.g., savings behaviors) relate to psychological factors as well as to individual risk preferences. We will then describe the tools and methods utilized before presenting our results. Afterward, we discuss our findings along with implications, to finalize with limitations, future work, and conclusions.

\section{Literature Review}

This section delves into ways of enhancing financial resiliency by incentivizing savings and discusses how saving behavior relates to psychological factors (e.g., personality traits). We also describe how the BART has been used to help elucidate these relationships, specifically in terms of individual risk preferences.

Financial Resiliency and Matched Savings Programs: Financial resiliency is the opposite of financial vulnerability and may be operationalized as individuals or households following minimal financial preparedness guidelines (such as having emergency funds equivalent to at least three months of living expenses) (Loke, 2016). Accordingly, scholars and policymakers have explored different ways of incentivizing such behaviors to enhance individuals' and households' ability to weather economic shocks, especially since low savings have remained an assiduous concern in the U.S. (Hall, 2021; Thaler, 1994). It may have been because of this that in the 1990s, asset-building programs, which entailed matched savings for home ownership, education, and small business capitalization, were instituted through individual development accounts (IDAs) (Sherraden et al., 2003). IDAs have been studied in relation to effective policy design (Sherraden, 2000) and have even been explored as the potential link between the savings inclinations of lowincome individuals and other policy instruments, such as federal and state income tax provisions targeted at them (Smeeding, 2005). However, counterintuitive results were uncovered, such as: total savings not increasing with income or savings rate actually decreasing with income (Sherraden et al., 2003). Or the savings outcomes of Caucasians depending on individual (i.e., socio-demographic) characteristics, while those of African Americans depended on institutional (programmatic) factors such as matching rates, automatic direct deposits, financial education, etc (Weiss \& Sherraden, 2005).

Despite their limited success (Loibl et al., 2018), IDA research provides "reason to believe that the poor can save if they are embedded in institutional conditions that promote saving" (Sherraden, 2008, p. 17). Insofar as 
access (e.g., having an account or being able to open one), facilitation (e.g., coaching, nudging) and expectations (e.g., having defined savings targets) could matter more than financial incentives (e.g., higher matching rates) (Sherraden, 2008). Thus, highlighting the tension between institutional approaches that deem context a more important driver of savings outcomes of matched savings programs than savers' individual characteristics (Birkenmaier et al., 2014). There are various aspects of IDA research that are relevant to this study. Most prominently, matched savings programs appear to help the poor save and build assets (Loke, 2016). In addition, institutional recommendations regarding the design of matched savings programs (e.g., expectations) were taken into consideration and are addressed in the methods section. However, here, we are also concerned with how personality traits may affect the financial behaviors of low income individuals.

Financial Behavior and Psychological Factors: Enhancing individuals' and households' financial behaviors are likely to entail augmenting their financial capabilities, which may be understood as the ability to make appropriate financial decisions, identifying adequate financial products and services, and understanding how to properly manage credit and debt (Mason \& Wilson, 2000). Doing so would help reduce welfare dependency, chronic indebtedness, stress levels, and associated ill-health (and other disparities), insofar as encouraging savings behavior can reduce financial vulnerability (and associated poverty increases). While also enhancing people's life opportunities (Taylor et al., 2011) along with their well-being (Shim et al., 2012). Now, since happier individuals tend to save more, as they tend to be less inclined to consume (Guven, 2012), there appears to be a virtuous cycle by which positive financial behaviors (such as savings) may enhance individuals' well-being and psychological health, and in turn, better psychological health (e.g., happiness) affects people's disposition to save.

However, seemingly simple actions, such as establishing a savings plan, require not only basic financial knowledge, but also key administrative skills, such as having a written savings goal/plan and following the plan, for instance, by watching expenses to ensure that they do not exceed income (Gutter et al., 2012). In particular, when versions of the above skills were captured and combined into a financial management behaviors score (FMBS); they were found to relate to the likelihood of having a savings account (i.e., access). Furthermore, having a savings account, in turn, depended on an individual's planning horizon, as well as the number of perceived barriers to savings (Gutter et al., 2012). But it would be perilous to simply assume that individuals will always have the cognitive bandwidth available to engage in future planning (Mullainathan \& Shafir, 2013). In sum, psychological and affective factors influence savings behavior. Indeed, it is "well established that psychological factors, such as the Big Five personality traits (agreeableness, conscientiousness, extraversion, neuroticism, and openness to experience)" along with "self-esteem, optimism, and trust are important predictors of economic behaviors" (Kesavayuth et al., 2018, p. 122). For instance, the extent to which adults (and even children) may find spending money to be painful, can be used to predict key financial behaviors and outcomes (e.g., credit scores, savings behavior, etc.) (Smith et al., 2018). Which in turn may help explain why consumers' financial health can be predicted using their aversion to high-cost financial products and services (Greenberg et al., 2020).

Moreover, the locus of control (LOC), a psychological construct associated to the extent to which individuals believe their actions help determine life outcomes, has been studied in relation to, among others, health behaviors (Conell-Price \& Jamison, 2015) and attitudes towards risk (Kesavayuth et al., 2018). Similar to the ways in which self-esteem has been shown to influence decision framing and risk-taking behavior (McElroy et al., 2007). In effect, when risk tolerance is understood as an individual's inclination to engage in behaviors that may result in uncertain and/or negative outcomes (Gambetti \& Giusberti, 2019), it seems intuitive to suppose that an individual's risk preferences (and associated personality traits) will affect their perception of how much control they can exert over life outcomes, including their savings and financial resilience. In light of this, it should be easy to see how trait anxiety could make individuals save money but also avoid investments, as anxious people tend to associate investments with high risks and low control. Conversely, investments tend to be made by individuals with high self-control, extraversion, and independence (Gambetti \& Giusberti, 2019). This is the case because an inflated sense of self-importance can be associated with greater risk-taking (Brunell \& Buelow, 2017). Perhaps because of this, extraversion is also associated with levels of debt and assets held (Brown \& Taylor, 2014). In sum, economic decisions involve real-life consequences associated with individuals' personalities and risk preferences (Ludwig et al., 2020). Because of this, capturing 
individuals' personality traits, and eliciting their risk preferences is essential for characterizing their economic and financial behaviors (Holzmeister, 2017). Which economists realized long ago while proposing that individuals' preferences and attitudes towards risk determined the curvature of their utility functions (Arrow, 1965). However, here, we are focused on the savings behavior, personality traits and risk preferences of low-income individuals.

Risk Preference Elicitation and the Balloon Analog Risk Task (BART) (Study 1): To help characterize the risk preferences of individuals in general, behavioral and cognitive neuroscience scholars have used tools such as the BART, a computerized decision-making paradigm that provides behavioral (lab-based) risk preference measures (Aklin et al., 2005; Lejuez et al., 2003; Lejuez et al., 2002). Risk preferences measured using the BART have been associated with both risk-taking propensity personality traits (e.g., sensation seeking, trait impulsivity) and real-world risky behaviors (e.g., substance abuse, smoking, gambling, unsafe, sex) (Fairley et al., 2019; Lejuez et al., 2003; Lejuez et al., 2002). The BART has also been used in behavioral economics research to investigate how decision-making under uncertainty is affected by age (Sproten et al., 2018), and in the behavioral finance literature as a risk preference elicitation tool (Holzmeister, 2017). Specifically, while completing the BART, participants are shown a series of 20 virtual balloons, one after another. Participants earn virtual money by "pumping up" each of those 20 balloons. This virtual money, earned while playing BART, "is stored on a temporary account until participants decide to collect the money (transfer it to a permanent account) and to proceed to the next balloon, or until the balloon pops", and any money accrued in the temporary account is lost (Sproten et al., 2018, p. 48). Thus, no BART earnings may be transferred from the temporary bank account into the permanent bank account from balloons that popped. Consequently, the permanent account is used to keep track of participants' total BART earnings from balloons that did not pop.

In this exploratory study, all participants completed three runs (each lasting approximately eight minutes) with 20 trials in each run, of the modified BART consisting of only blue balloons with an average break or pop point of 64 pumps. The original task had more balloon colors, with each color balloon having different average breakpoints, so that each set of balloon colors would expose participants to different risk levels. Now, in order to effectively elicit individuals' risk preferences, participants completed the BART after having been trained on the task and having had the opportunity to practice playing it. As explained above, participants were presented with a "virtual" balloon for which they had to guess the number of pumps it could withstand. Participants chose between 1 and 128 pumps using a scrolling device that collected participants' responses. The number of pumps guessed was defined either by scrolling upwards (to increase the number of pumps guessed) or scrolling downwards (to decrease the number of pumps guessed). If the balloon withstood more than the number of pumps guessed (i.e., participant placed a winning bet), the participant accrued one cent per pump. As such, higher pump bets can lead to more potential BART earnings. The chance that a balloon pops is randomly generated; however, the probability that a "balloon would explode on the first pump is $1 / 128$. If the balloon did not explode after the first pump, the probability that the balloon would explode was $1 / 127$ on the second pump, $1 / 126$ on the third pump, and so on up until the 128th pump, at which the probability of an explosion is 1/1 (i.e., 100\%)" (Lejuez et al., 2002, p. 77). Thus, higher pump bets confer greater risk, as the likelihood that the balloon will pop increases. Just as in the original BART application, participants were not given information about the probability of an explosion. They were simply told that at some point each balloon would explode and that this explosion could occur as early as the first pump (since some balloons could only withstand very few pumps), while others could withstand all the way up to 128 pumps.

Now, to model real-world situations in which excessive risk-taking results in diminishing returns, each successive pump on any particular balloon trial increased the amount to be lost because of an explosion while decreasing the relative gain of any additional pumps. For example, after the first pump, the next pump risks only 1 cent (accrued in the temporary bank) but could increase the possible earnings on that balloon by $100 \%$. However, after the 64 th pump, the next pump risks 64 cents accrued in the temporary bank and would increase possible earnings on that balloon trial by only 1.6\% (or 1/64) (Lejuez et al., 2002; Sproten et al., 2018). In essence, decreasing marginal returns to risk-taking after the 64th pump (or the mean break/pop point) is also built into the game. As explained above, the average break (or pop) point is 64 pumps, which is 
the mean at which expected BART earnings would be maximized and around which the balloons' break points are normally distributed (Figure. 1).

Figure 1: Expected BART Earnings as a Function of Average Pump Bet

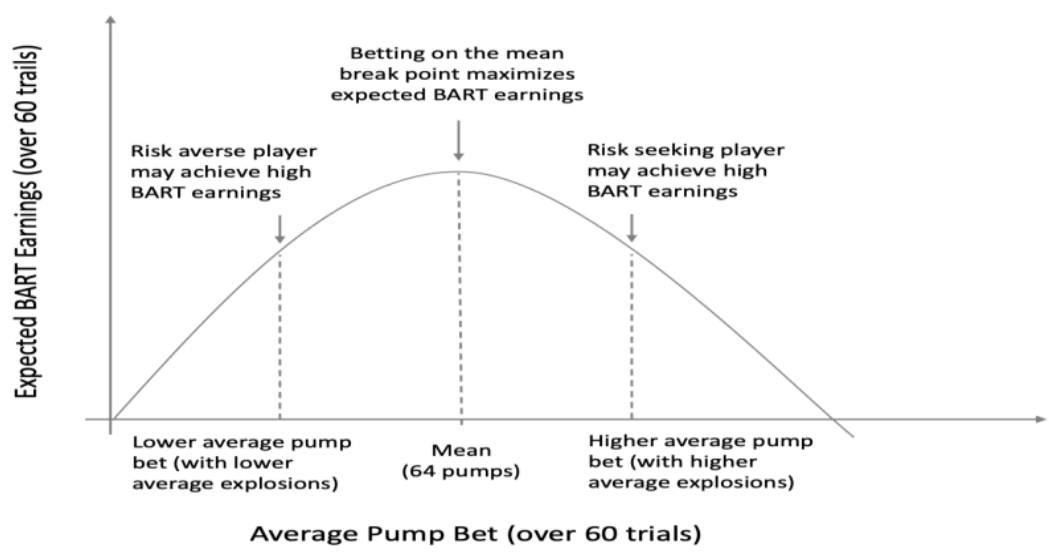

This means that relatively high earnings may be attained by risk-averse players who may choose to consistently place lower bets (while minimizing balloon explosions). As well as by risk-seeking players who may prefer placing larger bets (sustaining more balloon explosions). Note that players with adaptive risk preferences may decide, after noticing various balloons exploding consecutively at low break points (e.g., approximately 30 pumps), to place a larger size bet on the next balloon (e.g., approximately 100 pumps) realizing that its probability of withstanding a large number of pumps has increased (since the mean break point is 64 pumps). Which would, in turn, point to participants' ability to adapt risk preferences and be strategic about their risk-taking? This situation may help explain why Fairley et al. (2019, p. 15) assert that "the BART is not commonly used by economic scholars because of concerns that participants may not adequately comprehend uncertainty associated with the task and because of the resulting difficulty in relating participants' choices to standard risk models." In any case, once participants scrolled to their desired pump bet, they pressed the scroll button to lock in their response. This then triggered a screen showing a virtual balloon being inflated (Figure. 2). Subsequently, participants received feedback indicating whether they won the bet placed (and money from the temporary bank was moved to the permanent bank, adding to their total BART earnings) or the balloon popped. When participants placed a winning bet, the amount added to the accumulated total remained visible on the screen. However, if the balloon popped, no money was accrued, and the last balloon's break point remained visible on the screen. This outcome phase was followed by a "rest phase" during which participants waited for the next trial and got to bet on a new balloon.

\section{Figure 2: Modified BART}

In each trial, participants had to pump up a virtual balloon during the "pump phase" followed by a "wait phase" (i.e., where the participant waited for a few seconds). In the following "inflate phase", participants were presented with an animation of a balloon being inflated. An "outcome/feedback phase" followed the inflate phase, in which participants were presented with the outcome, i.e., that they had either won the reward or the balloon popped. 


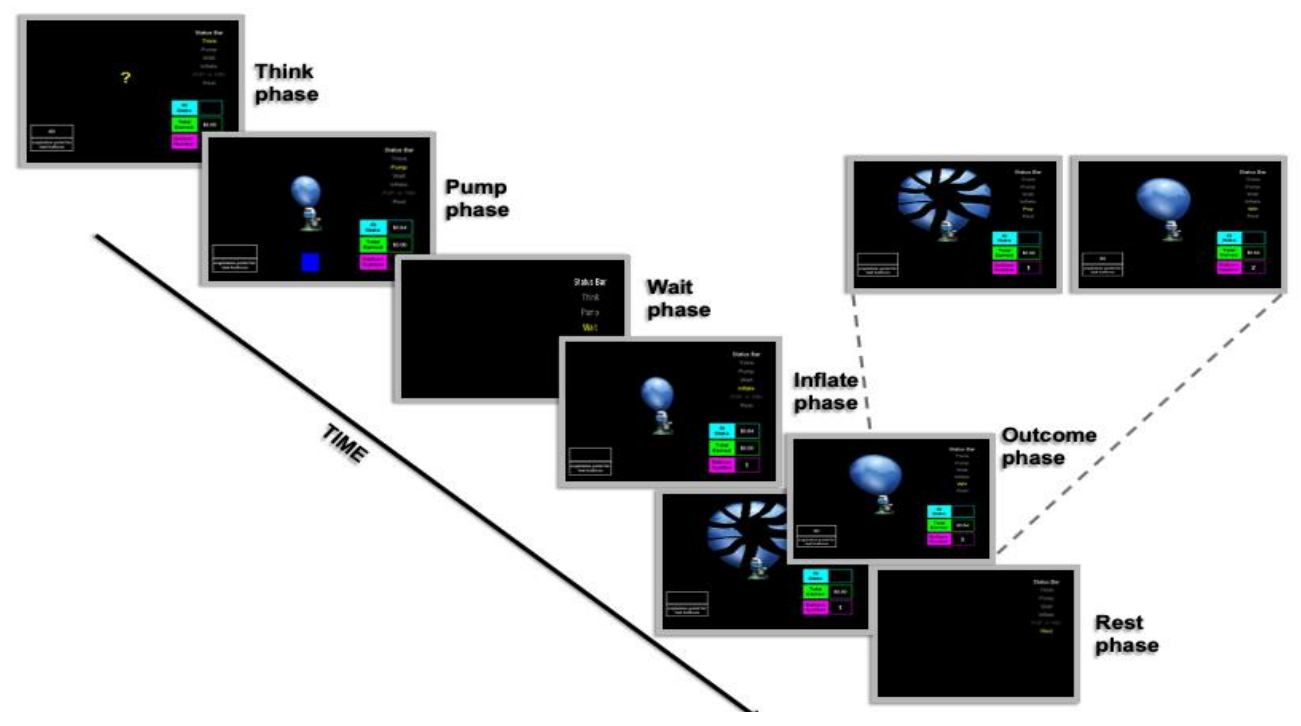

Personality Traits and Self-Report Surveys (Study 2): To characterize various aspects of participants' personalities, participants also completed eight self-report questionnaires: State-Trait Anxiety Inventory (STAI) (Spielberger et al., 1983), Barratt Impulsivity Scale (BIS) (Barratt, 1993), Delay Discounting Questionnaire (Kirby \& Maraković, 1996), Attitude Towards Risks (ATR) Questionnaire (Franken et al., 1992), Cognitive Failures Questionnaires (CFQ) (Broadbent et al., 1982), Toronto Alexithymia Scale (TAS) (Bagby et al., 1994), Behavioral Inhibiting System/Behavioral Activating System (BIS/BAS) (Voigt et al., 2009), and Temperament and Character Inventory (TCI) (Cloninger et al., 1994). Table 1 below details 28 personality metrics captured with these instruments.

Table 1: Personality Questionnaires and Metrics (Variables) Captured

\begin{tabular}{|c|c|c|c|}
\hline Items & $\begin{array}{l}\text { Self-report } \\
\text { Surveys } \\
\text { (Instrument) }\end{array}$ & $\begin{array}{l}\text { General } \\
\text { Description }\end{array}$ & $\begin{array}{l}\text { Personality Metrics (Variables) Captured and } \\
\text { Ranges }\end{array}$ \\
\hline $1-2$ & $\begin{array}{l}\text { State-trait } \\
\text { anxiety } \\
\text { inventory } \\
\text { (STAI) }\end{array}$ & $\begin{array}{l}\text { STAI is a } 40 \text {-item } \\
\text { questionnaire based on a } 4- \\
\text { point Likert scale. The STAI } \\
\text { measures two types of } \\
\text { anxiety: (a) state anxiety } \\
\text { and (b) trait anxiety. }\end{array}$ & $\begin{array}{l}\text { State anxiety: how a person is feeling at the time } \\
\text { regarding perceived threats (considered } \\
\text { temporary) } \\
\text { Range: } 23 \text { to } 49 \text { (a lower value means that the } \\
\text { respondent exhibits lower state anxiety, and a } \\
\text { higher value means higher state anxiety). } \\
\text { Trait anxiety: how people feel in typical situations } \\
\text { and on a daily basis (anxiety level as a personal } \\
\text { characteristic) } \\
\text { Range: } 36 \text { to } 54 \text { (a lower value means that the } \\
\text { respondent exhibits lower trait anxiety and a } \\
\text { higher value means higher trait anxiety). }\end{array}$ \\
\hline $3-7$ & $\begin{array}{l}\text { Barratt } \\
\text { impulsivity } \\
\text { scale (BIS) }\end{array}$ & $\begin{array}{l}\text { This scale is widely used as a } \\
\text { measure of impulsivity. It } \\
\text { includes } 30 \text { items that are } \\
\text { scored to yield six first- } \\
\text { order factors (attention, } \\
\text { motor, self-control, cognitive } \\
\text { complexity, perseverance, } \\
\text { and cognitive instability } \\
\text { impulsiveness), and three } \\
\text { second-order factors } \\
\text { (attentional, motor and non- }\end{array}$ & $\begin{array}{l}\text { BIS total: } \\
\text { Range: } 44 \text { to } 78 \text { (a lower value means lower } \\
\text { impulsivity, and a higher value means that the } \\
\text { respondent exhibits highly impulsive behavior). } \\
\text { BIS average: } \\
\text { Range: } 1.46 \text { to } 2.6 \text { (a lower value means lower } \\
\text { impulsivity, and a higher value means that the } \\
\text { respondent exhibits highly impulsive behavior). } \\
\text { Attentional sum: difficulty paying attention or } \\
\text { concentrating. } \\
\text { Range: } 9 \text { to } 24 \text { (a lower value means that the }\end{array}$ \\
\hline
\end{tabular}


planning impulsivity).

8

Delay
discounting
questionnaire

9

Attitude
towards Risk
(ATR)

10- Cognitive

13 failure

questionnaire (CFQ)
This is a 27-item, selfadministered questionnaire that assesses whether the participants prefer smaller immediate rewards over larger delayed rewards. This measure is scored by calculating whether the respondent's answers place him/her in the reference discounting curves, where placement amid steeply declining curves indicates a tendency to devalue rewards (i.e., higher levels of impulsivity).

ATR is a 34-item questionnaire that quantifies the subjects' attitudes towards risk.

$\mathrm{CFQ}$ is a 25-item questionnaire to assess the frequency with which people experience cognitive failures, such as absentmindedness, in everyday life. Slips and errors of perception, memory, and motor functioning. Summing scores across the relevant items yields subscale scores representing three dimensions: forgetfulness, distractibility, and false triggering. respondent has less difficulty concentrating, and a higher value means that the respondent has greater difficulties concentrating or paying attention).

Motor sum: person's ability to make up his/her mind.

Range: 14 to 36 (a lower value means that the respondent has a lower ability to make a quick decision, and a higher value means that the respondent has a higher ability to make a quick decision).

Non-planning sum: ability to plan for the future. Range: 14 to 32 (a lower value means a lower planning ability, and a higher value means a higher planning ability).

Range: 0.0001 to 0.25 (a lower value means that the respondent exhibits less delay discounting, lower impulsivity, indicated by preferring larger delayed rewards. In addition, a higher value means, higher discounting, higher impulsivity, indicated by preferring smaller immediate rewards).

Range: 77 to 157 (a lower value means that the respondent exhibits higher risky behavior and a higher value means that the respondent prefers lower risk-taking).

Range: 19 to 70 (a lower value means that the respondent exhibits lower absent-mindedness, and a higher value means higher absent-mindedness).

Forgetfulness: Tendency to let go from one's mind something known or planned, for example, names, intentions, appointments, or words.

Range: 7 to 28 (a lower value represents a lower amount of forgetfulness, and a higher value represents higher forgetfulness).

Distractibility: Being absentminded or easily disturbed in one's focused attention in social situations or interactions.

Range: 6 to 23 (a lower value represents lower distractibility, and a higher value represents higher distractibility).

False triggering: Interrupted processing of sequences of cognitive and motor actions.

Range: 3 to 21 (a lower value represents lower false triggering and a higher value represents higher false triggering) 
14- Toronto

17 alexithymia scale (TAS)
18-
TAS is a 20 -item instrument that is most commonly used as a measure of alexithymia. Alexithymia refers to the condition that involves having trouble identifying and describing emotions, as well as a tendency to minimize emotional experience and focus attention externally. This instrument has 3 subscales: Difficulty, describing feelings, difficulty identifying feelings, and externally oriented thinking.

The BIS/BAS is a 24-item self-report instrument designed to measure two motivational systems: the behavioral activation system (BAS), which captures goaloriented motivation; and the behavioral inhibition system (BIS), which alludes to motivation based on the avoidance of adverse outcomes.
TAS total:

Range: 29 to 73 (a lower value means that the respondent exhibits lower alexithymia and a higher value means higher alexithymia).

Difficulty describing feelings subscale: this subscale is used to measure difficulty describing emotions.

Range: 6 to 21 (a lower value means that the respondent exhibits less difficulty describing emotions and, a higher value means that the respondent exhibits more difficulty describing emotions).

Difficulty identifying feeling subscale: this subscale is used to measure difficulty identifying emotions.

Range: 7 to 27 (a lower value means that the respondent exhibits less difficulty identifying feelings, and a higher value means that the respondent exhibits greater difficulty identifying feelings).

Externally oriented thinking subscale: this subscale is used to measure the tendency of individuals to focus their attention externally.

Range: 8 to 25 (a lower value means that the respondent exhibits a lower tendency to focus attention externally, and a higher value means a higher tendency to focus attention externally).

BAS drive: corresponds to motivation based on goal-oriented outcomes.

Range: 7 to 16 (a lower value means a lower tendency to strive for something desired or lower appetitive motives, and a higher value means that the respondent exhibits higher appetitive motives).

BAS fun-seeking: motivation to find novel rewards spontaneously.

Range: 8 to 16 (lower values mean lower motivation to find novel rewards, and higher values mean higher motivation to find novel rewards).

BAS reward responsiveness: sensitivity to pleasant reinforcers in the environment

Range: 14 to 20 (lower values mean lower sensitivity to pleasant reinforcers, and higher values mean higher sensitivity to pleasant reinforcers).

BIS: corresponds to motivation to avoid adverse outcomes

Range: 9 to 26 (a lower value indicates lower adverse motives, or low desire to move away from unpleasant outcomes, and a higher value means that the respondent exhibits higher adverse motives 


\begin{tabular}{lllr}
\hline 22- & & The TCI is a & 240-item \\
28 & Temperament & questionnaire & that \\
and character & encompasses r seven \\
inventory & dimensions of personality \\
(TCI) & $\begin{array}{l}\text { traits. Four temperaments } \\
\text { (novelty seeking, harm }\end{array}$ \\
& avoidance, reward \\
& dependence, persistence) \\
& and three characters (self- \\
& directedness, r \\
& cooperativeness, \\
& transcendence).
\end{tabular}

Novelty-seeking: trait associated with exploratory activity in response to novel stimulation, impulsive decision making, quick loss of temper and avoidance of frustration

Range: 11 to 33 (a lower value means that the respondent exhibits lower novelty-seeking behavior and higher values mean that the respondent exhibits higher novelty-seeking behavior).

Harm avoidance: trait characterized by excessive worrying, pessimism, shyness and being fearful, doubtful and fatigued.

Range: 3 to 27 (a lower value means that the respondent exhibits lower harm avoidance behavior and a higher value means higher harm avoidance).

Reward dependence: trait characterized by the tendency to respond markedly to signals of reward, particularly to verbal signals of social approval, social support and sentiment

Range: 9 to 23, (a lower value means that the respondent exhibits lower reward dependence, and a higher value means higher reward dependence).

Persistence dimension: perseverance in spite of fatigue or frustrations

Range: 1 to 8 (a lower value means that the respondent exhibits lower persistence, and a higher value means that the respondent exhibits higher persistence).

Self-directedness: trait related ability to regulate and adapt behavior to the demands of situations to achieve personally chosen goals

Range: 17 to 39 (a lower value means that the respondent exhibits lower self-directed behavior, and a higher value represents higher self-directed behavior).

Cooperativeness dimension: trait concerning the degree to which a person is generally agreeable in their relationships with other people

Range: 22 to 42 (a lower value means that the respondent exhibits lower cooperativeness, and a higher value means that the respondent exhibits higher cooperativeness).

Self-transcendence: trait that involves the expansion of personal boundaries, including experiencing spiritual ideas.

Range: 13 to 30 (a lower value means that the respondent exhibits lower self-transcendence, and a higher value means that the respondent exhibits higher self-transcendence).

Studies 1 and 2 were part of an fMRI study in which all participants played the BART (as well as other tasks) while lying in an MRI scanner. Participants completed self-report surveys and were trained on how to complete behavioral tasks (including the BART) before entering the magnet. 


\section{Methods}

Participants: Potential participants were identified and enrolled in the study in collaboration with Catalyst Miami, a nongovernmental organization whose mission is to improve health, education, and economic opportunities in Miami. Catalyst Miami has a track record of connecting low-income families with financial services, such as tax preparation, credit building, savings opportunities, and financial coaching, through its community outreach programs. Individuals from different community outreach programs were recruited to participate in the study using advertisement flyers, which specified eligibility requirements, and were distributed by Catalyst Miami employees and coaches. Each participant completed a behavioral session and the 6mMSP. Before the behavioral session, all participants completed eight self-report personality questionnaires. We then explained to participants how to play the BART. Once they understood how to use the scrolling device to place bets, as well as the objective of the game, we proceeded to collect data while they played the BART on their own. Data were collected for 27 adult participants with low annual incomes (household incomes of approximately $\$ 20,000 / y r$.). These participants were then asked to open savings accounts to start the 6mMSP (more details on this savings program are given below). However, three participants were not able to open savings accounts, highlighting the importance of access (as described above). All volunteers were drug-free and had no current or past medical, neurological or psychiatric disorders. All participants signed written informed consent documents approved by Florida International University (FIU)'s IRB Ethical Committee. The study participants ( 14 female, 10 male) were all adult (average age $39.3 \pm 12.4$ years) low annual income individuals (average annual income $\$ 16,975 \pm \$ 5,472$ ). The group included racially and ethnically diverse individuals (Table 2) with relatively low educational attainment, specifically: 14 participants had a high school diploma (58.3\%), seven had earned an Associate's degree (29.16\%), and three had some college (12.5\%).

Table 2: Participant Demographics

\begin{tabular}{ll}
\hline Demographics & Participants $(\mathbf{n}=\mathbf{2 4})$ \\
\hline Race & 12 African American, 12 Caucasian \\
Ethnicity & 16 Hispanic, 8 Non-Hispanic \\
\hline
\end{tabular}

Procedures and Intervention: Following consent, participants first completed eight self-report surveys (study 2), were then trained on how to play BART, and subsequently completed the risk preference task (3 runs, each run consisting of 20 trials) (study 1). After successfully doing so, participants received payment and were then accompanied by a Catalyst Miami coach to open a savings account to start the $6 \mathrm{mMSP}$ (participants received a $\$ 70$ gift card and an additional $\$ 20$ were directly deposited into their newly opened savings account).

Intervention: Six-Month Matched Savings Program (6mMSP): After completing self-report surveys and the lab behavioral session, participants were enrolled in a matched saving program in which they needed to save \$20 each month for the following 6 months. Participants received a $\$ 10$ match for depositing each month's saving goal ( $\$ 20 /$ month), as well as a $\$ 60$ reward for completing the $6 \mathrm{mMSP}$ without any interim withdrawals (i.e., without touching their savings). We note that the first month's $\$ 20$ deposit was provided by the $6 \mathrm{mMSP}$, which by default generated the first $\$ 10$ match. In essence, every participant who managed to complete all self-report surveys played the BART and opened a savings account received $\$ 100$ (\$70 gift card, first month's $\$ 20$ direct deposit, and first month's $\$ 10$ match). If participants diligently deposited $\$ 20$ into their savings accounts for the following five months, they received a $\$ 10$ match each month from the $6 \mathrm{mMSP}$ until month six. Therefore, if participants saved $\$ 100$ ( $\$ 20 /$ month for five months), they stood to receive a $50 \%$ match (\$10/month for five months), which was a clearly defined monthly savings target and incentive for participants (i.e., expectations, another key institutional driver of savings outcomes). Moreover, if participants managed to complete the $6 \mathrm{mMSP}$ without any interim withdrawals, with at least $\$ 180$ (\$20/month deposits for six months, with $\$ 10 /$ month corresponding matches also for six months), they received an additional $33.33 \%$ matching reward of $\$ 60$ at the end of the savings program.

Participants who successfully completed the $6 \mathrm{mMSP}$ received $\$ 210$ in payments from the study, along with at least $\$ 100$ of their own money (some participants actually deposited more than the $\$ 20 /$ month required by the 6mMSP), for a total potential savings of at least $\$ 310$ (as participants could deposit more than the 
required amount). This amount of savings would significantly contribute to participants' ability to cope with nominal shocks (i.e., a $\$ 400$ emergency) and enhance their financial resiliency. In addition, this amount closely approximated the additional amount saved by individuals who participated in randomized control trials (RCTs) involving matched savings programs. In particular, Duflo et al. (2006) conducted an RCT and found that when individuals were offered matches to amounts saved (e.g., matches to their individual retirement account-IRA contributions), take-up rates, or individuals' willingness to participate in matched savings programs, increased as the percentage of IRA contributions matched also grew. This, in turn, helped make the treatment (or matched) group IRA contributions, on average, \$335 larger than the control (or unmatched) group contributions. Therefore, a suitable savings target was defined using reasonable expectations as well as sensible incentives that would capture real-life savings behavior in low-income populations. Participants' savings behavior was monitored by Catalyst Miami, and data were collected for the 24 participants who opened savings accounts and participated in the 6mMSP. Each participant's total savings at the end of the 6mMSP (i.e., total savings) was the main indicator considered in our analyses.

\section{Measures}

BART Performance Measures: Traditionally, the main dependent variables when using the BART (i.e., the essential BART key performance indicators - KPIs) are: the average number of pumps, calculated for trials in which the balloon did not explode, or adjusted pumps (Claus \& Hutchison, 2012), which we shall refer to here as the average pump bet, and total BART earnings (Kohno et al., 2016). In general, participants with higher average pump bets also experienced higher average balloon explosions, which is both intuitive and inherent to the BART's design (see Table 3 below). The highest total BART earnings ( $\$ 20.21$ ) were attained by MMMM005, with an average pump bet of 70.07 pumps (and average explosions of 4.77 balloons), and not by those who continuously placed higher pump bets (such as MMMM003 and MMMM009) or lower bets (such as MMMM001 and MMMM019), which is also inherent to BART's design.

Table 3: Traditional BART Performance Indicators and Effective Pump Bet

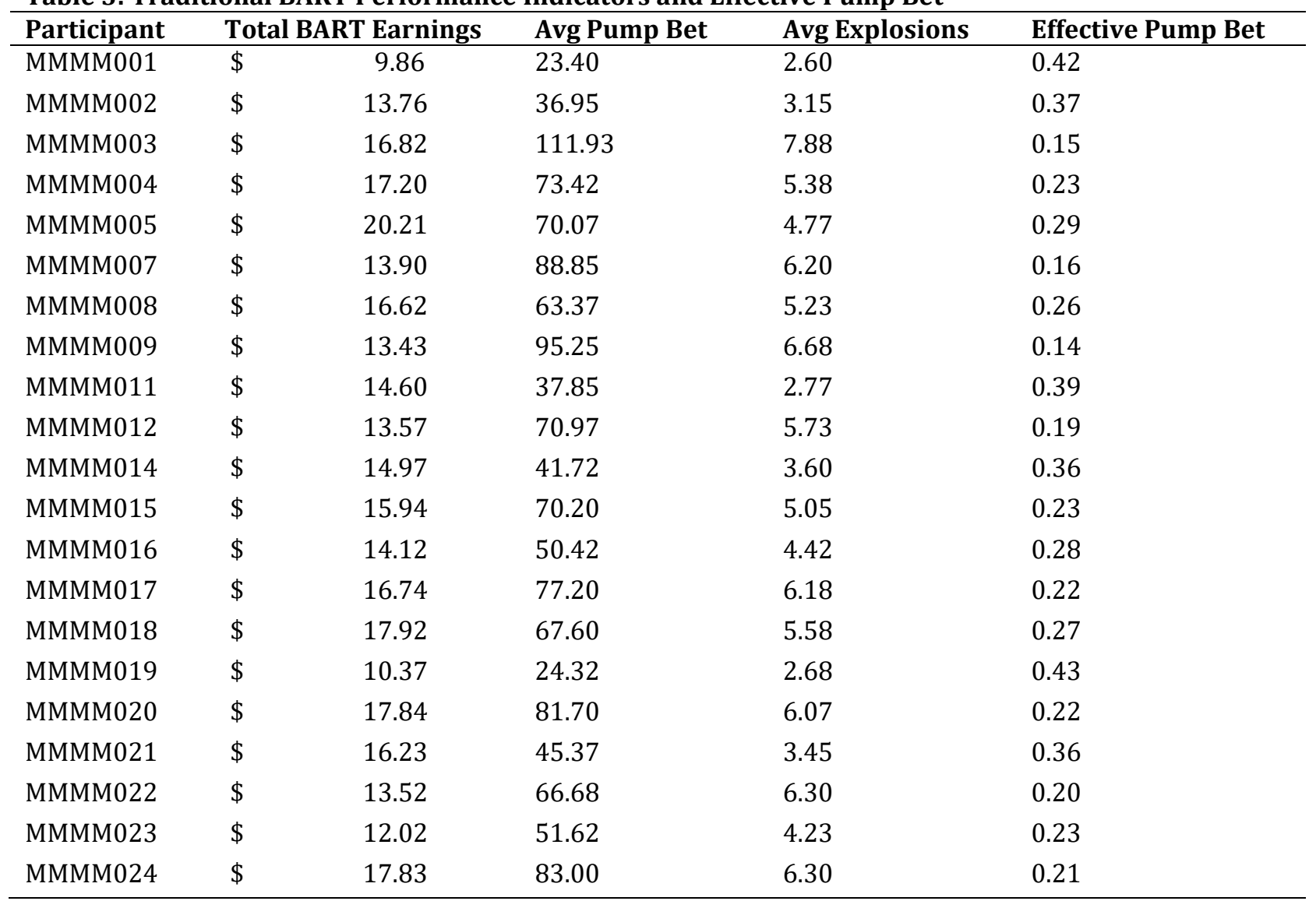




\begin{tabular}{llllll}
\multicolumn{5}{c}{$\begin{array}{c}\text { Journal of Economics and Behavioral Studies (ISSN: 2220-6140) } \\
\text { Vol. 13, No. 5, pp. 32-54, October 2021 }\end{array}$} \\
\hline \hline & \multicolumn{6}{c}{} \\
\hline MMMM025 & $\$$ & 16.19 & 51.37 & 4.38 & 0.32 \\
MMMM026 & $\$$ & 16.02 & 51.55 & 4.95 & 0.31 \\
MMMM027 & $\$$ & 16.83 & 47.62 & 3.52 & 0.35 \\
\hline
\end{tabular}

We note that MMMM016 attained $\$ 14.12$ with an average pump bet of 50.42 pumps (and average explosions of 4.42 balloons), while MMMM007 attained similar BART earnings (\$13.90) with a much higher average pump bet of 88.85 pumps and, thus, with much higher average explosions ( 6.2 balloons). As highlighted in Figure. 1 (as well as Figure. 3 below), risk-averse players (such as MMMM016) may attain similar BART earnings to those of risk seekers (i.e., MMMM007). In general, Figure. 3 also shows how our sample of lowincome participants exhibited the expected BART performance lab behavior.

\section{Figure 3: Total BART Earnings as a Function of the Average Pump Bet}

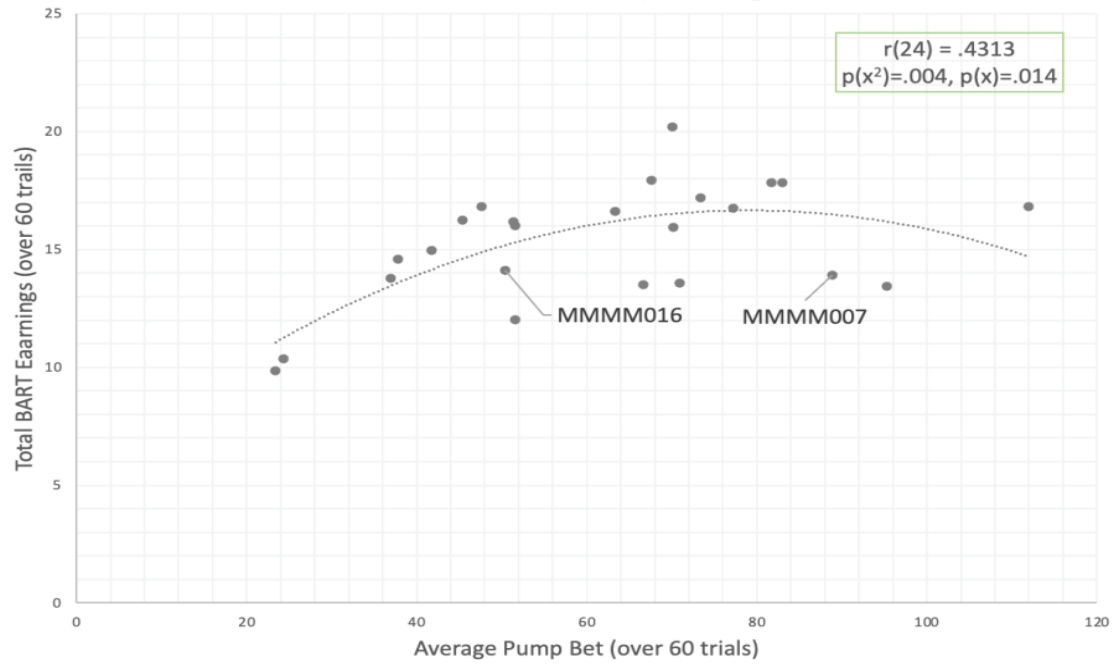

However, focusing on traditional BART KPIs, such as total BART earnings, would not differentiate MMMM007 from MMMM016. Additional risk-taking measures (such as the average pump bet or, conversely, average explosions, which are linear transformations of total pumps and total explosions, respectively) would be required to be able to effectively characterize each participant's risk preferences as either risk-seeking or risk-averse. This seems problematic on at least two fronts; first, two or more KPIs would be required to appropriately characterize a participant's risk preference effectively (i.e., whether participants attained the same BART earnings using more or less average pump bets). Second, traditional BART KPIs by themselves would not adequately capture how participants reacted to the fact that excessive risk-taking may result in diminishing returns (an essential feature of individuals' risk preferences and ATR).

Effective Pump Bet (New BART Key Performance Indicator): Therefore, we developed a new BART KPI, and normalized total BART earnings by average pump bet placed for each participant (across 60 trials). This new BART KPI, effective pump bet (EPB), not only allowed us to better characterize participants' behaviors in relation to the diminishing returns brought about by excessive risk-taking but also did so by means of only one (more comprehensive) performance measure. Indeed, participants may have exhibited relevant and adaptive risk preferences beyond recognizing that continuously betting the mean ( 64 pumps) could maximize their expected BART earnings. In particular, we posit that what should also matter is participants' ability to maximize BART earnings, from pump bets placed, by strategically adapting their risk preferences. As such, EPB helps differentiate MMMM007 from MMMM016, by evidence that the former only managed to squeeze $\$ 0.16$ per average pump bet by adopting a risk-seeking strategy, while the latter attained $\$ 0.28$ per average pump bet by adopting a much more conservative strategy (and performing 75\% better in EPB terms). 


\section{Results and Analysis}

Effective Pump Bet (EPB) and Real-Life Total Savings (Study 1): We conducted a bivariate Pearson's correlation analysis, using SPSS (version 26), of lab behavior (BART performance) using EPB, total explosions and adjusted pumps against total savings. We found that EPB was positively correlated with savings behavior $[\mathrm{r}(24)=0.58, \mathrm{p}=0.003]$, indicating that participants exhibiting adaptive risk preferences (while playing BART and measured using EPB) tended to end up with higher total savings (Figure. 4A). Meanwhile, the total number of balloon explosions was negatively correlated with savings behavior $[r(24)=-0.47, p=0.019]$, indicating that as the total number of explosions increased, total savings decreased (Figure. 4B). Finally, average pump bet or adjusted pumps (a traditional BART KPI) was not significantly related to total savings (Figure. 4C).

Figure 4: Relation between Laboratory Behavior (Bart Performance Measures) and Total Savings
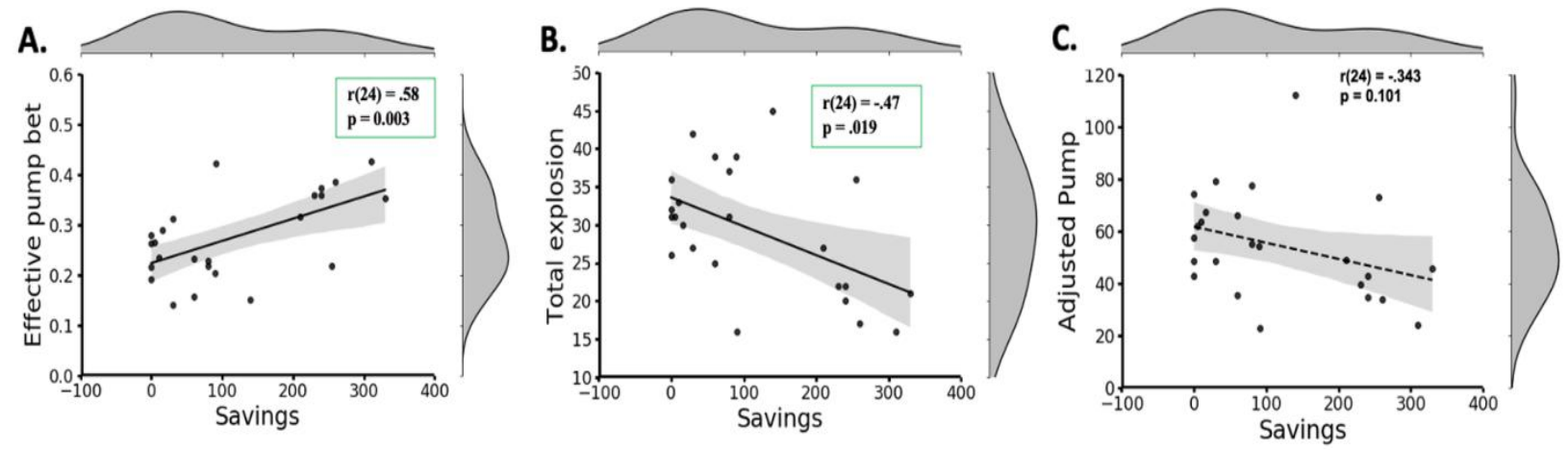

Grouping Participants Using Behavioral Measures (EPB) and Real-Life Total Savings: Figure. 4A shows that EPB explains almost $60 \%$ of the variation in total savings among study participants. We thus used EPB along with total savings (Table 4) to develop a standardized composite indicator of BART-Savings performance using principal components analysis (zPC-BS-Perf). This was done to consolidate lab and reallife performance measures and to simplify the exploration of personality traits affecting them both the most.

Table 4: Observed EPB, Total Savings and Composite Indicator of Bart-Savings Performance

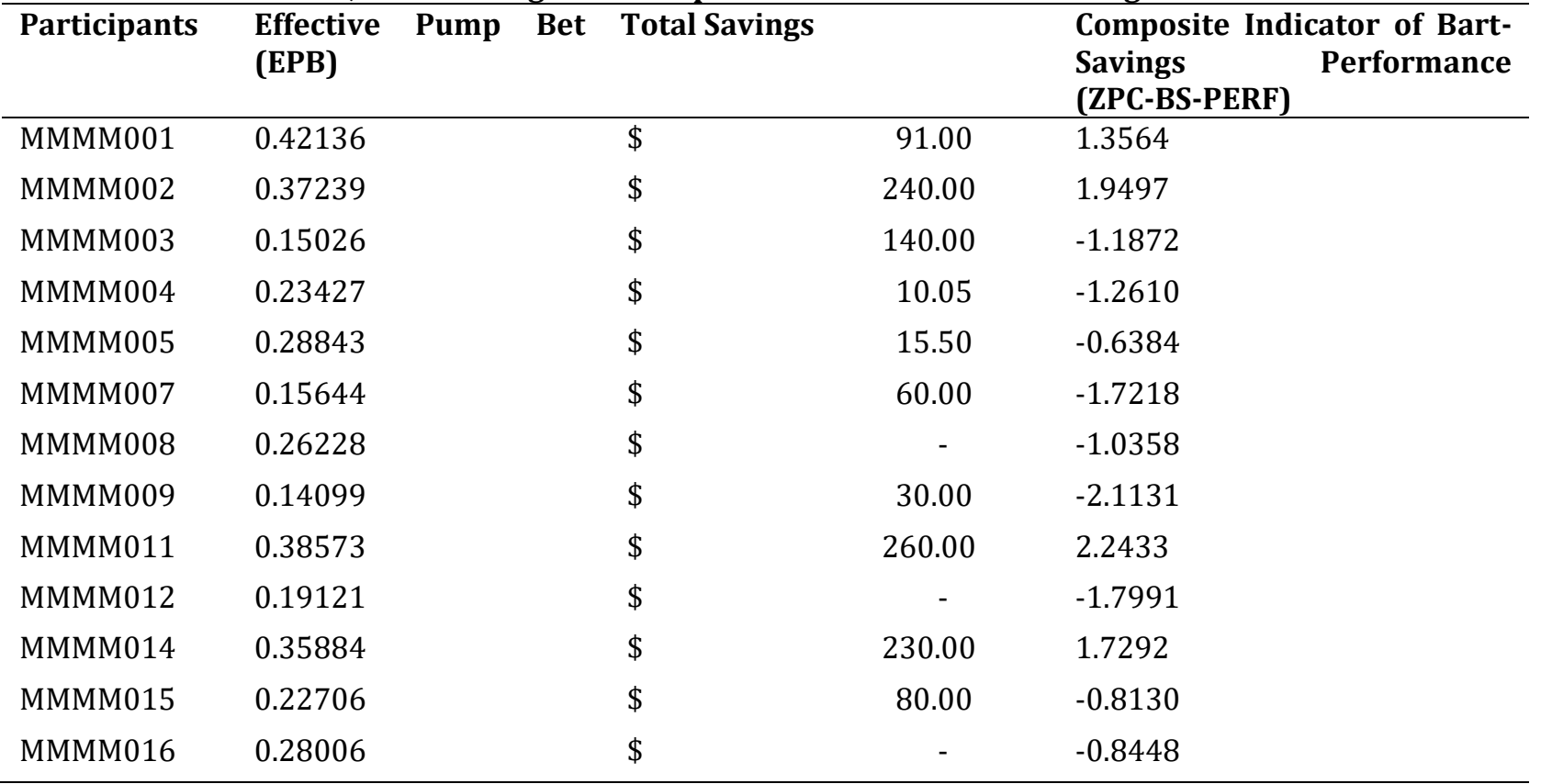




\begin{tabular}{lllcl}
\hline MMMM017 & 0.21683 & $\$$ & 255.00 & 0.3917 \\
MMMM018 & 0.26508 & $\$$ & 4.55 & -0.9715 \\
MMMM019 & 0.42645 & $\$$ & 310.00 & 3.05626 \\
MMMM020 & 0.21835 & $\$$ & 80.00 & -0.9065 \\
MMMM021 & 0.35778 & $\$$ & 370.00 & 2.7691 \\
MMMM022 & 0.20274 & $\$$ & 90.00 & -0.9991 \\
MMMM023 & 0.23287 & $\$$ & 60.00 & -0.9009 \\
MMMM024 & 0.21481 & $\$$ & - & -1.5455 \\
MMMM025 & 0.31518 & $\$$ & 210.00 & 1.1099 \\
MMMM026 & 0.31076 & $\$$ & 30.00 & -0.2897 \\
MMMM027 & 0.35344 & $\$$ & 330.00 & 2.4224 \\
\hline
\end{tabular}

Please note how, in Table 4, participants with high EPB and high total savings had a high positive zPC-BS-Perf score, while participants with low EPB and low total savings had negative zPC-BS-Perf scores.

Latent Personality Traits Associated to Laboratory and Real-Life Behaviors (Study 2): We also used EPB and total savings to perform hierarchical clustering analysis and group participants into high and lowperformance clusters. In particular, we utilized multiple hierarchical agglomerative methods (including Ward, Centroid and Average Distance), as well as divisive methods (based on correlations) to corroborate the stability of the clusters obtained (Everitt et al., 2011). Eight participants were classified in the highperformance cluster (MMMM001, 2, 11, 14, 19, 21, 25 and 27), and all others were grouped in the lowperformance cluster. As shown in Table A1 in the Appendix, participants' cluster assignments were consistent across all four methods. These clusters were then used as a binary target variable ( 1 for high-performance participants and 0 for low performance) in a partial least squares (PLS) model used to identify latent personality traits associated with high and low performance. PLS is useful when a few latent variables (among many input variables) contribute to most of the variation in the target variable values.

Specifically, we utilized a PLS node in SAS Enterprise Miner 14.1 to reduce the set of input and target variables to principal component matrices, such that input variable components could be used to predict the scores of target variable components. Subsequently, target variable component scores are used to predict target variable values (Wold et al., 1984). Now, in order to corroborate the stability of any emerging personality traits, we also used the standardized composite indicator of BART-savings performance (zPC-BSPerf) from Table 4 as a continuous target variable in a separate PLS model. In essence, PLS was used to identify which of the 28 personality metrics captured acted as latent personality traits with respect to the lab and real-life behaviors. Finally, we ran an additional model with two continuous target variables, first using lab behavior (standardized EPB - zEPB) as target variable and then real-life behavior (standardized total savings - zSav) as target variable (results in Table 5 below). 
Table 5: Latent Variable from Three PLS Models

\begin{tabular}{|c|c|c|c|c|}
\hline $\begin{array}{l}\text { Target } \\
\text { Variable and } \\
\text { Input } \\
\text { Variables }\end{array}$ & $\begin{array}{l}\text { One Binary Target } \\
\text { Variable (Hi Perf } \\
\text { Cluster }=1 \text {, lo Perf } \\
\text { Cluster }=0 \text { ) and } 28 \\
\text { Input Variables }\end{array}$ & $\begin{array}{lr}\text { One } & \text { Continuous } \\
\text { Target Variable } \\
\text { (zPC-BS-Perf) and } \\
28 \text { Input Variables }\end{array}$ & $\begin{array}{l}\text { Two Continuous Tary } \\
\text { zEPB as the Target } \\
\text { and } 28 \text { Input } \\
\text { Variables }\end{array}$ & $\begin{array}{l}\text { et Variables } \\
\text { zSav as the } \\
\text { and } 28 \\
\text { Variables }\end{array}$ \\
\hline $\begin{array}{l}\text { Model } \\
\text { specifications }\end{array}$ & 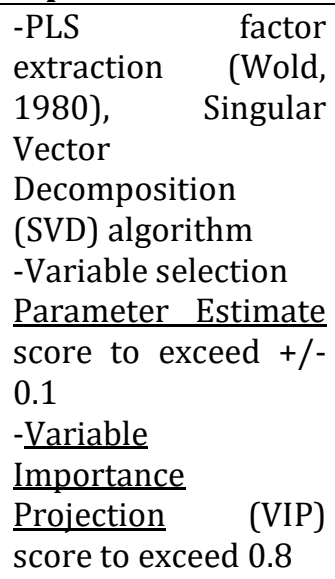 & $\begin{array}{l}\text {-PLS } \\
\text { extraction, } \\
\text { algorithm } \\
\text {-Variable selection } \\
\text { Parameter Estimate } \\
\text { score to exceed +/- } \\
0.1 \\
\text {-Variable Importance } \\
\text { Projection (VIP) } \\
\text { score to exceed } 0.8\end{array}$ & $\begin{array}{l}\text {-SIMPLS factor } \\
\text { extraction (De Jong, } \\
\text { 1993), SVD algorithm } \\
\text {-Variable selection } \\
\text { Parameter Estimate } \\
\text { score to exceed +/- } \\
0.1 \text {-Variable Importance } \\
\text { - Projection (VIP) } \\
\text { score to exceed 0.8 } \\
\text { zEPB as the target }\end{array}$ & 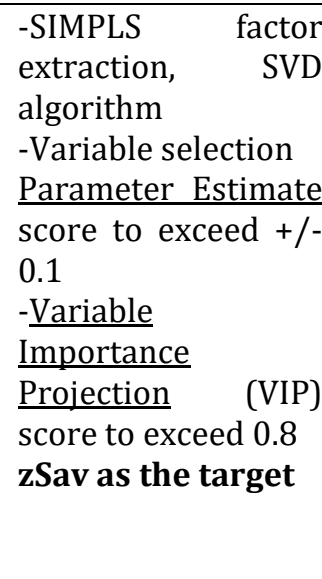 \\
\hline $\begin{array}{l}\text { Latent } \\
\text { variables } \\
\text { selected }\end{array}$ & $\begin{array}{l}\text { ATR } \\
\text { Distractibility } \\
\text { Perseverance } \\
\text { State Anxiety }\end{array}$ & $\begin{array}{l}\text { ATR } \\
\text { Distractibility } \\
\text { Perseverance } \\
\text { State Anxiety }\end{array}$ & $\begin{array}{l}\text { ATR } \\
\text { Cognitive Failure } \\
\text { Distractibility } \\
\text { State Anxiety }\end{array}$ & $\begin{array}{l}\text { ATR } \\
\text { Attentional factor } \\
\text { Perseverance } \\
\text { State Anxiety } \\
\text { BIS } \\
\text { Self-directedness }\end{array}$ \\
\hline Comment & & & $\begin{array}{l}\text { Distractibility has } \\
\text { an important effect } \\
\text { on zEPB }\end{array}$ & $\begin{array}{l}\text { State anxiety has } \\
\text { an important effect } \\
\text { on zSav }\end{array}$ \\
\hline
\end{tabular}

As expected, attitude towards risk (ATR) was selected as a latent variable in all four models (Table 5), as well as state anxiety, which also seemed intuitive given that our study focused on low-income participants (who may have felt uncomfortable coming to a university, completing long surveys, getting in a magnet, playing BART, etc.). Meanwhile, distractibility and perseverance were also selected as latent personality traits while using the groupings obtained through clustering as binary target variable, as well as while using zPC-BS-Perf as a continuous target variable. For the two continuous target variables model, distractibility had an effect on the standardized EPB (zEPB), while state anxiety had an effect on the standardized total savings (zSav). Because of this, ATR, state anxiety, distractibility and perseverance were identified as the latent personality traits contributing most to BART and savings performance.

Composite Indicator of Latent Personality Traits: These four latent personality traits contributing most to BART and savings performance, were then standardized and combined into a composite indicator of latent personality traits (PC4) using principal component analysis. Please see Table 6 below. 
Table 6: Standardized Attitude towards Risk, State Anxiety, Distractibility and Perseverance, As Well as the Composite Indicator of Latent Personality Traits

\begin{tabular}{|c|c|c|c|c|c|}
\hline Participant & zATR & $\begin{array}{l}\text { zState_A } \\
\text { nxiety }\end{array}$ & zDistractibility & zPerseverance & $\begin{array}{l}\text { Composite Indicator of Latent } \\
\text { Personality Traits (PC4) }\end{array}$ \\
\hline MMMM001 & 1.7 & 1.346 & 0.705 & 0.857 & -0.63247 \\
\hline MMMM002 & 1.625 & 1 & 0.705 & 1 & -1.47997 \\
\hline МMMМ003 & 1.513 & 1.307 & 1.352 & 0.714 & 2.51230 \\
\hline MMMM004 & 1.85 & 1.423 & 1 & 0.142 & 2.59828 \\
\hline MMMM005 & 1.35 & 1.884 & 0.529 & 1.142 & -1.02577 \\
\hline MMMM007 & 1.025 & 1.538 & 1.058 & 1 & 1.34262 \\
\hline MMMM008 & 0.963 & 1.346 & 1.117 & 1 & 1.36184 \\
\hline MMMM009 & 1.413 & 1.076 & 0.882 & 0.857 & -0.02099 \\
\hline MMMM011 & 1.413 & 0.961 & 0.470 & 0.714 & -1.41511 \\
\hline MMMM012 & 1.13 & 1.153 & 0.764 & 1 & -0.49889 \\
\hline MMMM014 & 1.713 & 1.230 & 1.058 & 0.714 & 1.01612 \\
\hline MMMM015 & 1.963 & 1.5 & 0.705 & 1 & -1.10121 \\
\hline MMMM016 & 1.8 & 1.538 & 0.705 & 0.428 & 0.80394 \\
\hline MMMM017 & 1.8 & 1.461 & 0.941 & 0.857 & 0.37211 \\
\hline MMMM018 & 1.54 & 1.076 & 0.882 & 1 & -0.57119 \\
\hline MMMM019 & 1.63 & 0.961 & 0.352 & 1.142 & -3.3664 \\
\hline MMMM020 & 1.34 & 1.269 & 1.058 & 0.714 & 1.46324 \\
\hline MMMM021 & 1.78 & 1 & 0.529 & 1 & -2.34151 \\
\hline MMMM022 & 1.75 & 1.269 & 0.764 & 0.714 & -0.14205 \\
\hline MMMM023 & 1.363 & 0.884 & 0.823 & 1.143 & -1.32471 \\
\hline MMMM024 & 1.738 & 0.923 & 0.705 & 0.714 & -0.86987 \\
\hline MMMM025 & 1.613 & 1.576 & 0.941 & 1.142 & -0.10361 \\
\hline MMMM026 & 1.28 & 1.153 & 1.294 & 0.571 & 2.71991 \\
\hline MMMM027 & 1.35 & 0.884 & 1.117 & 0.857 & 0.70338 \\
\hline
\end{tabular}

Please note that lower zATR values point to risk-seeking preferences, while higher values mean risk-averse preferences. Similarly, for zPerseverance, lower values indicate lower persistence, and higher values indicate the opposite. The principal component weights associated with these two variables were negative $(-0.158$ and -0.406, respectively), which meant that participants for whom ATR and perseverance had large, weighted contributions to PC4 -in terms of significant risk-averse behavior and high-end persistence-had negative overall scores for the composite indicator of latent personality traits (PC4) affecting BART and savings performance. In contrast, participants with high state anxiety as well as high distractibility (with principal component weights of 0.217 and 0.574 , respectively), along with lower negative contributions associated with risk-averse behavior and high persistence, had positive PC4 scores.

Mediation Analysis: Using SPSS (version 26), we conducted a bivariate Pearson's correlation analysis between PC4 and lab behavior (i.e., EPB) and real-world behavior (i.e., total savings). The results indicated that latent personality scores (from PC4) significantly negatively correlated with our measure of adaptive risk preferences, EPB $[r(24)=-0.447, p=0.02]$, indicating that as the score on the latent personality measure increased, savings decreased (Figure. 5A). Similarly, the latent personality score was significantly negatively correlated with real-world savings behavior and savings $[\mathrm{r}(24)=-0.392, \mathrm{p}=0.05]$, indicating that as the latent personality score increased, savings decreased (Figure. 5B). 


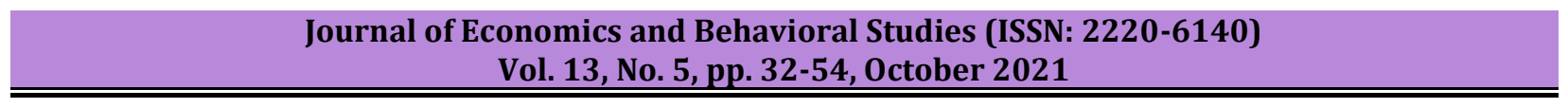

\section{Figure 5: Relationship between Latent Personality Traits (Pc4), Lab Behavior (EPB) and Real-World Behavior (Total Savings)}

(A) PC4 is significantly negatively correlated with EPB $[r(24)=-0.447, p=0.02]$. (B) PC4 is significantly negatively correlated with total savings $[r(24)=-0.392, p=0.05]$. (C) Mediation model showing the relation between latent personality traits (in PC4), lab behavior (BART performance in terms of EPB), and real-life behavior (as total savings). EPB fully mediated the effect of latent personality traits (PC4: X) on total savings (Y) as (1) PC4 accounted for the significant variance in EPB (a path); (2) EPB accounted for the unique variance in total savings when controlling for PC4 (b path); (3) the indirect mediation effect was significant (ab path); and (4) PC4's direct effect on total savings was not significant when EPB was included in the model. ${ }^{*} p<0.05$. Since PC4 exhibited a significant correlation with both EPB (Figure. 5A) and savings (Figure. $5 \mathrm{~B}$ ), we conducted a mediation analysis using SPSS PROCESS V3.4 to examine whether the relation between PC4 (i.e., a composite indicator of latent personality traits) (X).

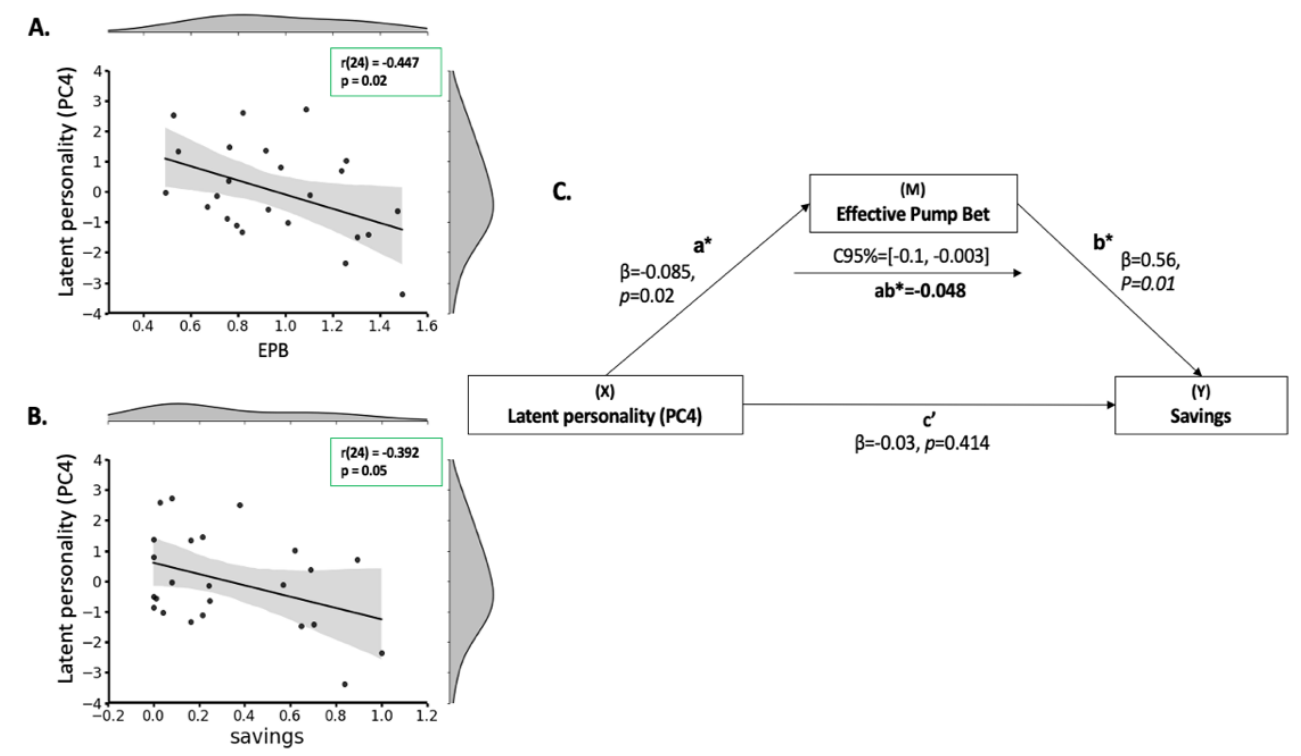

Real-world behavior (i.e., total savings) (Y) could be explained by lab behavior (M, BART task performance in terms of EPB). In other words, we conducted the mediation analysis to test the hypothesis that the effect of PC4 (X) on total savings (Y) was mediated by EPB (M). As shown in Figure. 5C, EPB fully mediated the influence of PC4 on total savings. Specifically, when including EPB as a mediator in the model, PC4's direct effect on total savings failed to reach significance ( $c^{\prime}$ path: $\beta=-0.03, p=0.414$ ), whereas the indirect effect was significant (ab path: $\beta=-0.048$ : 95\% CI $=-0.01,-0.003$ ). This suggests that higher PC4 scores predict decreases in EPB. In addition, even though higher EPB predicted higher total savings, higher PC4 scores decreased total savings by decreasing EPB. In essence, latent personality traits (i.e., attitude towards risk, state anxiety, distractibility and perseverance) affected the risk preferences of low-income individuals, in turn impacting their ability to take full advantage of matched savings programs, save, and become financially resilient.

\section{Discussion}

To help start elucidating the way in which these four latent personality traits may affect individual risk preferences and, subsequently, real-life savings behavior of low-income individuals, we will now discuss how each may influence individuals' decision-making processes, in particular their risk preferences. Regarding attitudes towards risk, captured using the 34-item Attitudes Toward, Risk Scale (ATRS), having a propensity to take physical and/or psychological risks should not be expected to contribute to individuals' ability to place effective pump bets or to save. Insofar as ATRS scores can be associated with increased sensationseeking and impulsivity. Interestingly, access to formal savings-among otherwise unbanked populations- 
helped delay their inclination to take risks (Carvalho et al., 2016). In terms of state anxiety, which is a subscale of the State-Trait Anxiety Inventory (STAI) questionnaire, and reflects the more temporary condition of anxiety (captured through feelings of apprehension, tension, nervousness and concern) (Spielberger et al., 1983). Previous studies have discovered that people with lower anxiety were more likely to save regularly among individuals from low and moderate-income households (Hayhoe et al., 2012), which stands in juxtaposition with the more generalized role that trait anxiety plays in making individuals of all backgrounds save more but invest less, as discussed above (Gambetti \& Giusberti, 2019). In general, it does not seem counterintuitive to suppose that lower state anxiety, through the influence it may exert on risk preferences, should enhance individuals' ability to place effective pump bets and to save.

Distractibility is a subscale of the Cognitive Failure Questionnaire (CFQ) and is identified as a disturbance in the individual's ability to focus attention (Hadlington, 2015). Unsurprisingly, measures of distractibility relate to other personality traits (e.g., proneness to become bored or the need to seek excitement), behavioral tendencies (e.g., hyperactivity and impulsiveness) as well as to cognitive functioning (e.g., failure of concentration or focus) (Kass et al., 2010). Thus, it seems intuitive that lower distractibility would enhance individuals' ability to place effective pump bets and to save. Finally, regarding perseverance (or persistence), which is defined as an individual's tendency to maintain behaviors despite frustration and fatigue (Cloninger et al., 1994). As such, perseverance may be expected to help facilitate adherence to norms, rules and programs. Thus, perseverance may enhance individuals' ability to save. The above points combined ought to help shed additional light on how high PC4 scores could decrease total savings by decreasing participants' ability to place effective pump bets (or strategically adapt risk preferences).

Implications: Our findings could help refine interventions aimed at enhancing financial resiliency among low-income populations through the use of matched savings programs. For instance, depending on participants' BART performance-matched savings programs could be offered in a manner that maximizes the number of participants likely to successfully complete them. In essence, EPB could help identify individuals who are most likely to readily take full advantage of savings opportunities. This in turn could also help avoid the stipulation of unnecessary (and expensive) financial coaching programs to these same individuals. Now, behavioral decision-making researchers have already considered using BART to identify real-world risktakers (Schürmann et al., 2019). Here we propose using new BART performance measures (e.g., EPB), to customize matched savings programs by means of tailored (participant-focused) accompanying coaching sessions. This way, participants deemed less likely to successfully complete matched savings programs, based on their BART performance (captured using EPB), could then be offered varying levels of attention and customized coaching, based on their PC4 scores. Which, once again, could avoid the stipulation of generalized (and perhaps ineffective) coaching services? Specifically, the examination of how zPC-BS-Perf varies as a function of PC4 for our sample (Figure. 6) points to ways of defining the intensity and periodicity of coaching services associated with matched savings programs (using participants' PC4 scores). 
Figure 6: BART-Savings Performance as a Function of Latent Personality Traits

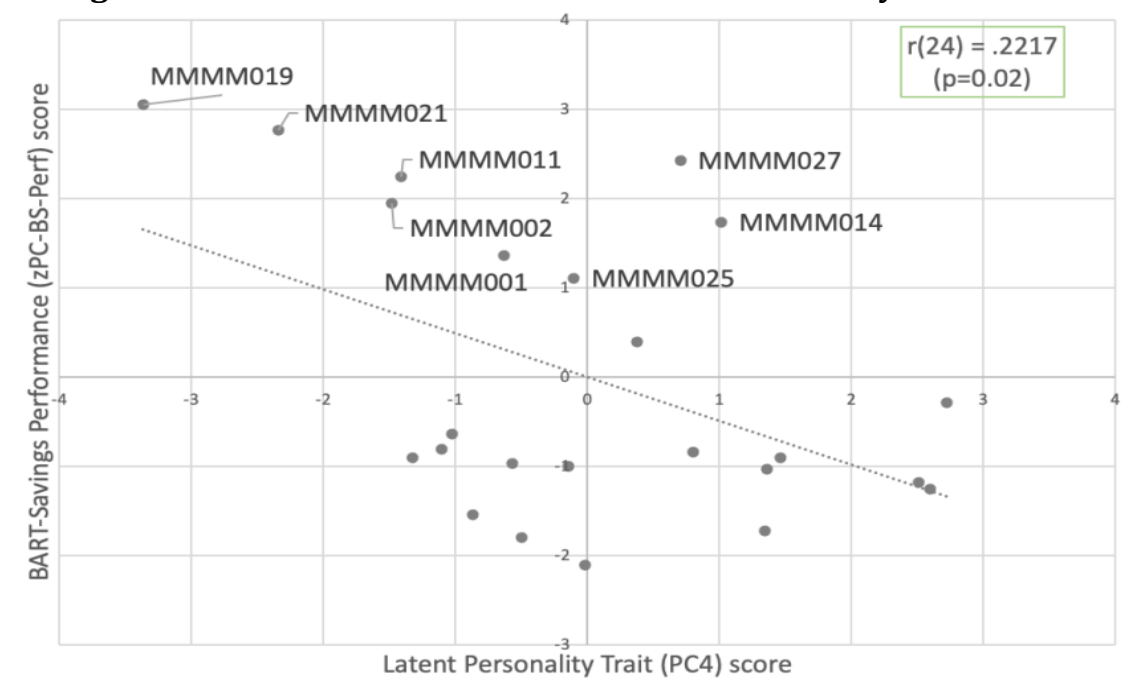

Figure. 6 shows that low-income individuals with higher risk-seeking attitudes, higher state anxiety, higher distractibility and lower persistence exhibit lower overall BART-savings performance. In fact, we expect each point subtracted from the PC4 score to increase zPC-BS-Perf by $49.22 \%$. As such, customized coaching sessions could be aimed at helping participants develop strategies to manage their state anxiety and distractibility to improve their attitude towards risk while enhancing their persistence, and thus improving participants' chances of completing matched savings programs.

Limitations and Future Research: Our study should be replicated with a larger group of low-income participants. In addition, considering the inclusion of a control group of high-income individuals could help tease out any potential low-income condition effects on state anxiety. As expected, exploring the savings behavior of low-income individuals was not a trivial endeavor. In particular, we experienced unexpected and surprisingly long delays in recruitment, which may be associated with individuals' reluctance to enroll in savings opportunities due to repeated previous inaction (Krijnen et al., 2020). As discussed in the introduction, inaction inertia may not only be more pronounced in low-income contexts but may also be adversely influencing participants' ability to strategically adapt their risk preferences (another aspect that should be explored in future research). In addition, cognitive scarcity among low-income populations-by which exacting daily struggles consume individuals' brain power, thus leaving little bandwidth to engage in future planning (Mullainathan \& Shafir, 2013) - should be explored in light of our findings. For instance, neurocognitive mechanisms (or substrates) associated with cognitive capacity (such as working memory) that may affect low-income individuals' savings ability should be explored. Moreover, neurocognitive substrates associated with risk preferences (elicited through BART) underpinning low-income individuals' ability to save should also be studied.

\section{Conclusion}

The COVID-19 pandemic and the economic wreckage it continues to bequeath are surely exacerbating the financial perils of many households and individuals the world over. Here, we set out to explore how personality traits could help define risk preferences, which in turn could affect the savings behavior of lowincome individuals. In particular, we explored the relationship between 28 personality metrics, traditional lab (BART) performance measures, and real-life savings behaviors of 24 low-income participants (clients of Catalyst Miami). We uncovered the influence that four latent personality traits (encompassed in PC4) exerted on participants' ability to strategically adapt their risk preferences (captured using a new BART performance measure - EPB), which subsequently affected their savings behavior. Despite the exploratory nature of this study, our efforts yielded a new BART measure that could help policymakers, funders, practitioners, and notfor-profits optimize their impact by identifying low-income individuals more likely to readily take advantage of matched savings programs. As this new BART measure is associated with four personality traits, it should 
also help customize financial coaching services for low-income individuals less likely to do so. Our hope is that these findings can contribute to the development of more effective savings programs at a time when they could play a vital role in helping mitigate financial vulnerability.

\section{References}

Aklin, W. M., Lejuez, C., Zvolensky, M. J., Kahler, C. W. \& Gwadz, M. (2005). Evaluation of behavioral measures of risk-taking propensity with inner-city adolescents. Behavior Research and Therapy, 43(2), 215228. https://doi.org/10.1016/j.brat.2003.12.007

Arrow, K. J. (1965). Aspects of the Theory of Risk-Bearing. Yrjö Jahnsonian Sätiö.

Bagby, R. M., Parker, J. D. \& Taylor, G. J. (1994). The twenty-item Toronto Alexithymia Scale-I. Item selection and cross-validation of the factor structure. Journal of psychosomatic research, 38(1), 23-32. https://doi.org/https://doi.org/10.1016/0022-3999(94)90005-1

Barratt, E. S. (1993). Impulsivity: Integrating cognitive, behavioral, biological, and environmental data. In The Impulsive Client: Theory, Research, and Treatment (pp. 39-56). American Psychological Association. https://doi.org/https://doi.org/10.1037/10500-003

Birkenmaier, J., Curley, J. \& Kelly, P. (2014). Matched savings account program participation and goal completion for low-income participants: Does financial credit matter? Journal of Social Service Research, 40(2), 215-231. https://doi.org/10.1080/01488376.2013.875095

Broadbent, D. E., Cooper, P. F., FitzGerald, P. \& Parkes, K. R. (1982). The cognitive failures questionnaire (CFQ) and its correlates. British journal of clinical psychology, 21(1), 1-16. https://doi.org/https://doi.org/10.1111/j.2044-8260.1982.tb01421.x

Brown, S. \& Taylor, K. (2014). Household finances and the 'Big Five'personality traits. Journal of Economic Psychology, 45, 197-212.

Brunell, A. B. \& Buelow, M. T. (2017). Narcissism and performance on behavioral decision-making tasks. Journal of Behavioral Decision Making, 30(1), 3-14.

Carvalho, L. S., Prina, S. \& Sydnor, J. (2016). The effect of saving on risk attitudes and intertemporal choices. Journal of Development Economics, 120, 41-52. https://doi.org/10.1016/j.jdeveco.2016.01.001

CBPP. (2020). Tracking the COVID-19 Recession's Effects on Food, Housing, and Employment Hardships. Center on Budget and Policy Priorities. https://www.cbpp.org/research/poverty-andinequality/tracking-the-covid-19-recessions-effects-on-food-housing-and

Claus, E. D. \& Hutchison, K. E. (2012). Neural mechanisms of risk-taking and relationships with hazardous drinking. Alcoholism: Clinical and Experimental Research, 36(6), 932-940. https://doi.org/10.1111/j.1530-0277.2011.01694.x

Cloninger, C. R., Przybeck, T. R., Svrakic, D. M. \& Wetzel, R. D. (1994). The Temperament and Character Inventory (TCI): A guide to its development and use. Center for Psychobiology of Personality, Washington University.

Conell-Price, L. \& Jamison, J. (2015). Predicting health behaviors with economic preferences \& locus of control. Journal of Behavioral and Experimental Economics, 54, 1-9. https://doi.org/10.1016/j.socec.2014.10.003

De Jong, S. (1993). SIMPLS: An alternative approach to partial least squares regression. Chemometrics and Intelligent Laboratory Systems, 18(3), 251-263. https://doi.org/10.1016/0169-7439(93)85002-X

Duflo, E., Gale, W., Liebman, J., Orszag, P. \& Saez, E. (2006). Saving incentives for low-and middle-income families: Evidence from a field experiment with H\&R Block. The Quarterly Journal of Economics, 121(4), 1311-1346. https://doi.org/10.1162/qjec.121.4.1311

Everitt, B. S., Landau, S., Leese, M. \& Stahl, D. (2011). Cluster Analysis. John Wiley \& Sons.

Fairley, K., Parelman, J. M., Jones, M. \& Carter, R. M. (2019). Risky health choices and the balloon economic risk protocol. Journal of Economic Psychology, 73, 15-33.

Franken, R. E., Gibson, K. J. \& Rowland, G. L. (1992). Sensation seeking and the tendency to view the world as threatening. Personality and Individual Differences, 13(1), 31-38. https://doi.org/10.1016/01918869(92)90214-A

Gabler, N. (2016, May 2016). The secret shame of middle-class Americans. The Atlantic, 317.

Gambetti, E. \& Giusberti, F. (2019). Personality, decision-making styles and investments. Journal of Behavioral and Experimental Economics, 80, 14-24. https://doi.org/10.1016/j.socec.2019.03.002 
Gauthier, A. H. \& Furstenberg, F. F. (2010). The experience of financial strain among families with children in the United States. Working Paper WP-10-17. National Center for Family \& Marriage Research.

Greenberg, A. E., Sussman, A. B. \& Hershfield, H. E. (2020). Financial product sensitivity predicts financial health. Journal of Behavioral Decision Making, 33(1), 15-26.

Gutter, M. S., Hayhoe, C. R., DeVaney, S. A., Kim, J., Bowen, C. F., Cheang, M., Cho, S. H., Evans, D. A., Gorham, E. \& Lown, J. M. (2012). Exploring the relationship of economic, sociological, and psychological factors to the savings behavior of low-to moderate-income households. Family and Consumer Sciences Research Journal, 41(1), 86-101. https://doi.org/10.1111/j.1552-3934.2012.02130.x

Guven, C. (2012). Reversing the question: Does happiness affect consumption and savings behavior? Journal of Economic Psychology, 33(4), 701-717. https://doi.org/10.1016/j.joep.2012.01.002

Hadlington, L. J. (2015). Cognitive failures in daily life: Exploring the link with Internet addiction and problematic mobile phone use. Computers in Human Behavior, 51, 75-81. https://doi.org/10.1016/j.chb.2015.04.036

Hall, C. C. (2021). Promoting savings for financial resilience: Expanding the psychological perspective. Current Directions in Psychological Science, 30(1), 49-54. https://doi.org/10.1177/0963721420979603

Hayhoe, C. R., Cho, S. H., DeVaney, S. A., Worthy, S. L., Kim, J. \& Gorham, E. (2012). How do distrust and anxiety affect saving behavior? Family and Consumer Sciences Research Journal, 41(1), 69-85. https://doi.org/10.1111/j.1552-3934.2012.02129.x

Holzmeister, F. (2017). oTree: Ready-made apps for risk preference elicitation methods. Journal of Behavioral and Experimental Finance, 16, 33-38. https://doi.org/10.1016/j.jbef.2017.08.003

Kass, S. J., Beede, K. E. \& Vodanovich, S. J. (2010). Self-report measures of distractibility as correlates of simulated driving performance. Accident Analysis \& Prevention, 42(3), 874-880. https://doi.org/10.1016/j.aap.2009.04.012

Kesavayuth, D., Ko, K. M. \& Zikos, V. (2018). Locus of control and financial risk attitudes. Economic Modeling, 72, 122-131. https://doi.org/10.1016/j.econmod.2018.01.010

Kirby, K. N. \& Maraković, N. N. (1996). Delay-discounting probabilistic rewards: Rates decrease as amounts increase. Psychonomic bulletin $\&$ review, 3(1), 100-104. https://doi.org/https://doi.org/10.3758/BF03210748

Kohno, M., Nurmi, E. L., Laughlin, C. P., Morales, A. M., Gail, E. H., Hellemann, G. S. \& London, E. D. (2016). Functional genetic variation in dopamine signaling moderates prefrontal cortical activity during risky decision making. Neuropsychopharmacology, 41(3), 695-703. https://doi.org/10.1038/npp.2015.192

Krijnen, J. M., Zeelenberg, M., Breugelmans, S. M. \& van Putten, M. (2020). Inaction inertia in retirement saving. Journal of Behavioral Decision Making, 33(1), 52-62.

Lejuez, C. W., Aklin, W. M., Jones, H. A., Richards, J. B., Strong, D. R., Kahler, C. W. \& Read, J. P. (2003). The balloon analog risk task (BART) differentiates smokers and nonsmokers. Experimental and Clinical Psychopharmacology, 11(1), 26-33. https://doi.org/10.1037/1064-1297.11.1.26

Lejuez, C. W., Read, J. P., Kahler, C. W., Richards, J. B., Ramsey, S. E., Stuart, G. L., Strong, D. R. \& Brown, R. A. (2002). Evaluation of a behavioral measure of risk-taking: The Balloon Analogue Risk Task (BART). Journal of Experimental Psychology: Applied, 8(2), 75-84. https://doi.org/10.1037/1076-898X.8.2.75

Liu, H. H. \& Chou, H. Y. (2018). Promotional formats and inaction inertia. Journal of Economic Psychology, 66, 22-32.

Loibl, C., Jones, L. \& Haisley, E. (2018). Testing strategies to increase saving in individual development account programs. Journal of Economic Psychology, 66, 45-63.

Loibl, C., Kraybill, D. S. \& DeMay, S. W. (2011). Accounting for the role of habit in regular saving. Journal of Economic Psychology, 32(4), 581-592.

Loke, Y. J. (2016). Financial preparedness for income shock among Malaysians. Malaysian Journal of Economic Studies, 53(2), 279-295.

Ludwig, J., Jaudas, A. \& Achtziger, A. (2020). The role of motivation and volition in economic decisions: Evidence from eye movements and pupillometry. Journal of Behavioral Decision Making, 33(2), 180195.

Lusardi, A. (2011). Americans' Financial Capability. National Bureau of Economic Research (NBER) Working Paper 17103. National Bureau of Economic Research. 
Lusardi, A., Schneider, D. J. \& Tufano, P. (2011). Financially fragile households: Evidence and implications. National Bureau of Economic Research (NBER) Working Paper No. 17072. National Bureau of Economic Research.

Mason, C. L. J. \& Wilson, R. M. S. (2000). Conceptualizing Financial Literacy (Vol. 7). Business School, Loughborough University.

McElroy, T., Seta, J. J. \& Waring, D. A. (2007). Reflections of the self: how self-esteem determines decision framing and increases risk-taking. Journal of Behavioral Decision Making, 20(3), 223-240.

Mullainathan, S. \& Shafir, E. (2013). Scarcity: Why Having too Little Means So Much. Macmillan.

Schürmann, O., Frey, R. \& Pleskac, T. J. (2019). Mapping risk perceptions in dynamic risk-taking environments. Journal of Behavioral Decision Making, 32(1), 94-105.

Sherraden, M. (2000). From research to policy: Lessons from individual development accounts. Journal of Consumer Affairs, 34(2), 159-181. https://doi.org/10.1111/j.1745-6606.2000.tb00089.x

Sherraden, M. (2008). IDAs and Asset-Building Policy: Lessons and Directions. Center for Social Development, George Warren Brown School of Social Work, Washington University.

Sherraden, M., Schreiner, M. \& Beverly, S. (2003). Income, institutions, and saving performance in individual development accounts. Economic Development Quarterly, 17(1), 95-112. https://doi.org/10.1177/0891242402239200

Shim, S., Serido, J. \& Tang, C. (2012). The ant and the grasshopper revisited: The present psychological benefits of saving and future-oriented financial behaviors. Journal of Economic Psychology, 33(1), 155-165.

Smeeding, T. M. (2005). The EITC and USAs/IDAs: Maybe a Marriage Made in Heaven? Working Paper 00-18. Center for Social Development, George Warren Brown School of Social Work, Washington University.

Smith, C. E., Echelbarger, M., Gelman, S. A. \& Rick, S. I. (2018). Spendthrifts and tightwads in childhood: Feelings about spending predict children's financial decision making. Journal of Behavioral Decision Making, 31(3), 446-460.

Spielberger, C. D., Gorsuch, R. L., Lushene, R., Vagg, P. R. \& Jacobs, G. A. (1983). State-Trait Anxiety Inventory for Adults. Consulting Psychologists Press Inc. PsycNET [WWW Document]. URL https://psycnet.apa.org/record/9999-06496-000?doi=1

Sproten, A. N., Diener, C., Fiebach, C. J. \& Schwieren, C. (2018). Decision making and age: Factors influencing decision making under uncertainty. Journal of Behavioral and Experimental Economics, 76, 43-54. https://doi.org/10.1016/j.socec.2018.07.002

Taylor, M. P., Jenkins, S. P. \& Sacker, A. (2011). Financial capability and psychological health. Journal of Economic Psychology, 32(5), 710-723. https://doi.org/10.1016/j.joep.2011.05.006

Thaler, R. H. (1994). Psychology and savings policies. The American Economic Review, 84(2), 186-192.

Voigt, D. C., Dillard, J. P., Braddock, K. H., Anderson, J. W., Sopory, P. \& Stephenson, M. T. (2009). BIS/BAS scales and their relationship to risky health behaviors. Personality and Individual Differences, 47(2), 89-93. https://doi.org/https://doi.org/10.1016/j.paid.2009.02.003

Weiss, M. G. \& Sherraden, M. (2005). Racial differences in performance in a matched savings program. Journal of Income Distribution, 13(3-4), 6.

Westfall, J. E., Jasper, J. D. \& Christman, S. (2012). Inaction inertia, the sunk cost effect, and handedness: Avoiding the losses of past decisions. Brain and cognition, 80(2), 192-200.

Wold, H. (1980). Model construction and evaluation when theoretical knowledge is scarce: Theory and application of partial least squares. In J. Kmenta \& J. B. Ramsey (Eds.), Evaluation of Econometric Models (pp. 47-74). Academic Press.

Wold, S., Ruhe, A., Wold, H. \& Dunn III, W. (1984). The collinearity problem in linear regression. The partial least squares (PLS) approach to generalized inverses. SIAM Journal on Scientific and Statistical Computing, 5(3), 735-743. https://doi.org/10.1137/0905052 


\section{Appendix}

Table A1: Results of Clustering Participants using Four Different Methods

\begin{tabular}{lllll}
\hline & \multicolumn{2}{l}{ Hierarchical Clustering Approach } & & \\
Subject & Waglomerative & $\begin{array}{l}\text { Methods } \\
\text { Centroids }\end{array}$ & Average Distance & Divisive Methods \\
\hline MMMM001 & Cluster1 & Cluster1 & Cluster1 & Cluster1 \\
MMMM002 & Cluster1 & Cluster1 & Cluster1 & Cluster1 \\
MMMM003 & Cluster2 & Cluster2 & Cluster2 & Cluster2 \\
MMMM004 & Cluster2 & Cluster2 & Cluster2 & Cluster2 \\
MMMM005 & Cluster2 & Cluster2 & Cluster2 & Cluster2 \\
MMMM007 & Cluster2 & Cluster2 & Cluster2 & Cluster2 \\
MMMM008 & Cluster2 & Cluster2 & Cluster2 & Cluster2 \\
MMMM009 & Cluster2 & Cluster2 & Cluster2 & Cluster2 \\
MMMM011 & Cluster1 & Cluster1 & Cluster1 & Cluster1 \\
MMMM012 & Cluster2 & Cluster2 & Cluster2 & Cluster2 \\
MMMM014 & Cluster1 & Cluster1 & Cluster1 & Cluster1 \\
MMMM015 & Cluster2 & Cluster2 & Cluster2 & Cluster2 \\
MMMM016 & Cluster2 & Cluster2 & Cluster2 & Cluster2 \\
MMMM017 & Cluster2 & Cluster2 & Cluster2 & Cluster2 \\
MMMM018 & Cluster2 & Cluster2 & Cluster2 & Cluster2 \\
MMMM019 & Cluster1 & Cluster1 & Cluster1 & Cluster1 \\
MMMM020 & Cluster2 & Cluster2 & Cluster2 & Cluster2 \\
MMMM021 & Cluster1 & Cluster1 & Cluster1 & Cluster1 \\
MMMM022 & Cluster2 & Cluster2 & Cluster2 & Cluster2 \\
MMMM023 & Cluster2 & Cluster2 & Cluster2 & Cluster2 \\
MMMM024 & Cluster2 & Cluster2 & Cluster2 & Cluster2 \\
MMMM025 & Cluster1 & Cluster1 & Cluster1 & Cluster1 \\
MMMM026 & Cluster2 & Cluster2 & Cluster2 & Cluster2 \\
MMMM027 & Cluster1 & Cluster1 & Cluster1 & Cluster1 \\
\hline & & & & \\
\hline
\end{tabular}

Acknowledgements: This exploratory study was funded by Catalyst Miami (and JPMorgan Chase) through Award AWD000000006374 (Project 800006841) as well as by Florida International University's (FIU) Graduate School Dissertation Year Fellowship. Study was carried out at FIU's Center of Imaging Sciences (CIS). We are grateful to Catalyst Miami for being such a patient and devoted partner. 